\title{
Science in culture
}

\section{Books \& arts}

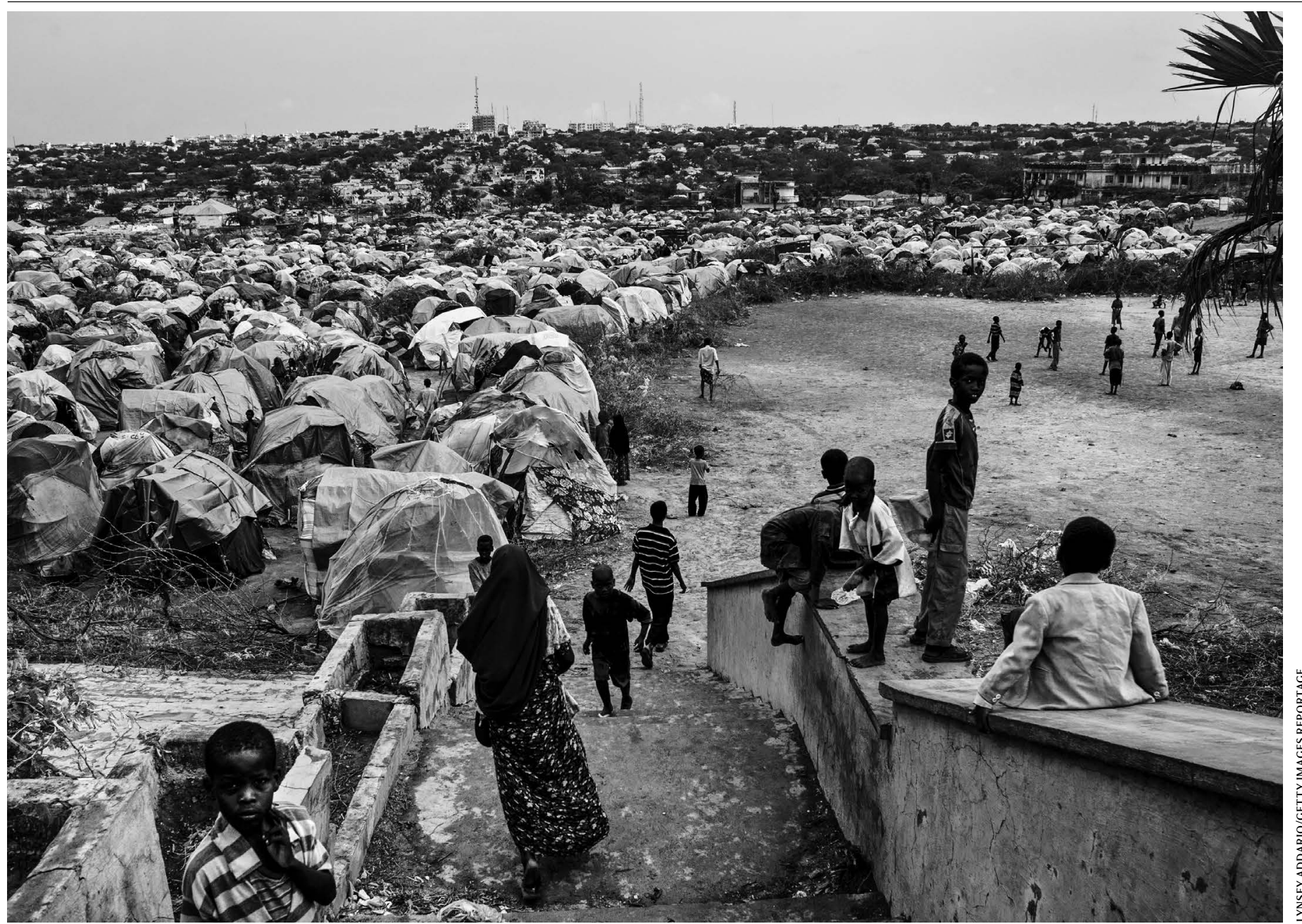

Many Somali refugees live in the crowded Dadaab camp for displaced people in Kenya, after fleeing droughts in their country.

\section{Migration is normal-accept it}

\section{Pull down the walls, argues a book on the movement of people, animals and plants. By Emma Marris}

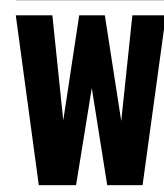

hen the coronavirus pandemicled to stay-at-home orders around the globe, we all felt, at once, how central to human life movement is. Prevented from leaving our neighbourhoods, we became isolated, nervous, claustrophobic. Were we experiencing some Zugunruhe, the 'migratory restlessness' that seizes birds when it is time to take flight?
This near-universal disruption of how our species operates is another piece of evidence to add to the studies and anecdotes collected by journalist Sonia Shah to support her claim that migration is not aberrant, but is "an unexceptional ongoing reality". The Next Great Migration anticipates movements - human and non-human -in response to climate change as just the latest chapter in a story as old as life itself. Such migrations, she posits, are natural, common and largely harmless.

Shah convincingly argues that politicians against immigration distort and misuse data to create unnecessary and cruel barriers. She tells gut-wrenching stories of struggling families on the move, and presents evidence that migrants are generally healthier and less apt to commit violent crimes than are the residents of the country they move to. And studies show that immigrants benefit host economies.

Turning to plants and animals, she takes biologists to task for abusing data to make introduced species look worse than they are. She charges that renowned ecologist Charles Elton "cherry-picked" case studies of the most disruptive introduced species (such as the sea lamprey (Petromyzon marinus), which originated in the Atlantic Ocean and devastated trout populations in the Great Lakes). She levels that later biologists exaggerated the economic impact of non-natives by including the costs of 
removing them in calculations. Shah concludes that invasion biologists' predictions of "ecological Armageddon" have failed to transpire.

As a writer on ecology and conservation (for example, my 2011book Rambunctious Garden), my expertise lies with the non-human migrations that Shah covers. I found it odd that she tends to group together many kinds of biological movement that specialists think of as quite different. Annual migrations - such as those of bar-headed geese (Anserindicus), which fly over the Himalayas on yearly trips from Mongolia to India and back again - as well as seed dispersal and animals roaming to find new territories and mates, aren't generally seen as comparable to human-mediated translocations across oceans, such as the deliberate introduction of Asian turtles in Hawaii to be bred for food. The former are considered natural, valuable processes; the latter are deemed unnatural, generally undesirable and potentially dangerous. Yet, Shah often ignores the human role.

Perhaps that's part of her point. The way we judge species' movements is a product of our culture, after all, and the borders we draw might be as arbitrary as those between our nation states. People are simply primates with iPhones; why should the species we carry be treated differently from those that move without us? If monkeys could arrive in the New World 30 million years after the Atlantic Ocean formed; if sweet potatoes could raft to Polynesia on their own; if seeds from Hawaii's koa tree could find purchase on the island of Réunion, half a world away, then even transoceanic range shifts are perfectly natural. How else could remote islands have developed any 'native' flora and fauna at all?

Most invasion biologists counter that philosophical discussions of 'naturalness' don't get us very far. Their concern is the effect on the travellers' new homes. The fact that many organisms move about widely of their own accord is not, in itself, evidence that introduced species can't be a problem. Most non-natives don't establish a population, or they have no unwanted effects - as Elton wrote, "There are enormously more invasions that never happen, or fail quite soon or even after a good many years." But a few do take hold. Some - mostly on islands or in lakes threaten local inhabitants with extinction.

Such extinctions have surely occurred after long-distance range shifts that people had nothing to do with. The sudden arrival of rodents in South America 41 million years ago, for example, probably had far-reaching effects on the ecosystems there. Indeed, millions of years of planet-wide movements - including,

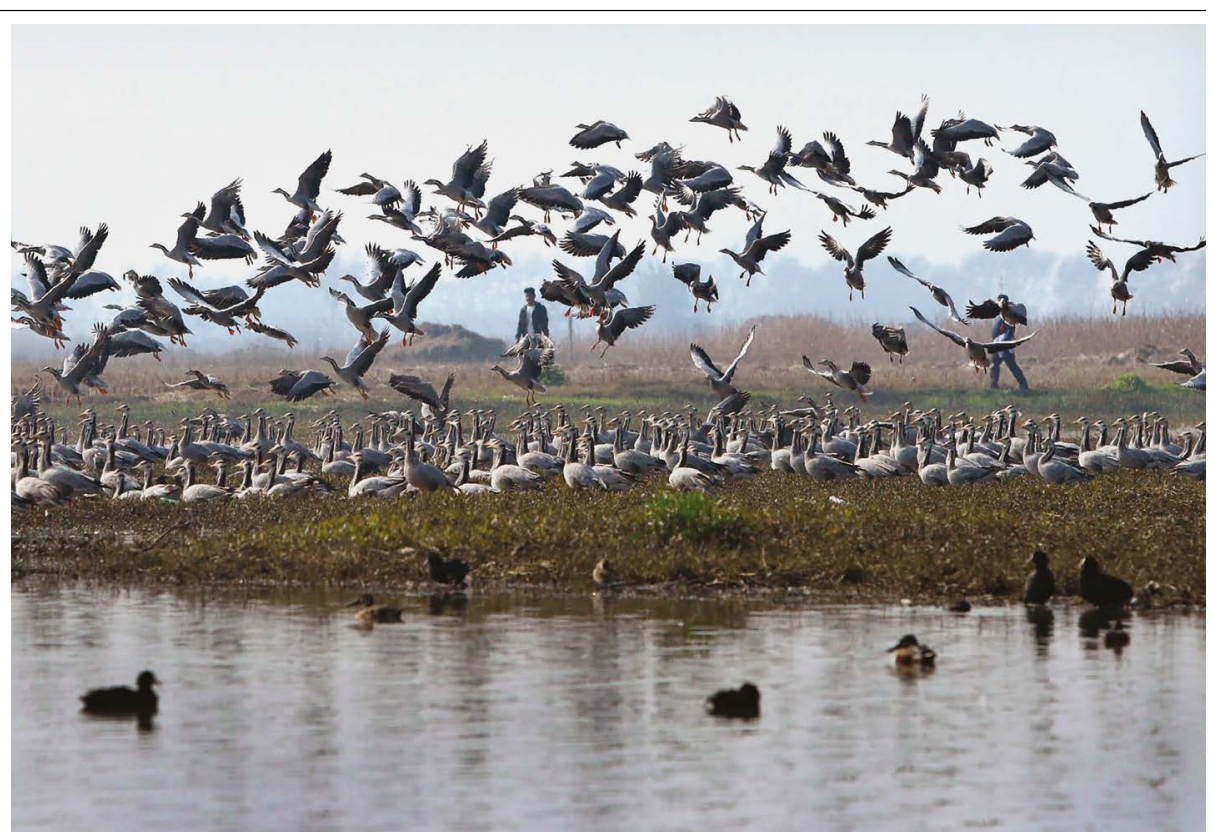

Bar-headed geese, which migrate from Tibet and central Asia each winter, near Jammu, India.

in the past few millennia, journeys of animals and plants as stowaways or as travelling companions of humans - have shaped the ecosystems we are trying to protect.

But the pace of radical range shifts in today's world is immeasurably higher. Before humans got to Hawaii, 30 new species made it there every million years. In the past 2 centuries, the islands have seen about 20 new species show up each year. And there is an ethical argument to be made that, when humansmovespecies, we have a collective responsibility to mitigate the consequences. Cats and foxes that were introduced to Australia after European settlement in 1788 have helped to wipe out 22 native mammal species, such as the desert bandicoot (Perameles eremiana) and lesser stick-nest rat (Leporillus apicalis). Many introduced species will not cause significant problems. But if we wish to prevent extinctions, then a subset of these introduced species must be managed in some way. Shah does not parse these subtleties with the degree of nuance that specialists might want.

I do agree with her, however, that it is absolutely worth comparing our attitudes

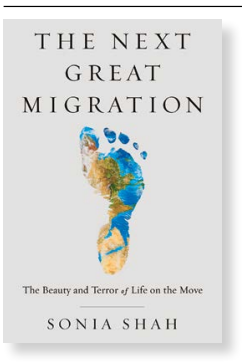

towards human and non-human migrants, especially as climate change increases all such movements - our temporary lockdown notwithstanding. As Earth heats, trees climb mountains, butterflies flutter north and birds nest in new places. Humans, too, are relocating in a flow "from south to north along the gradient of our warming planet", Shah writes. She predicts that the biggest and most lasting human movements will be those sparked by persistent droughts. And climate migration won't be a straightforward, predictable human tide. Each story of migration is unique, she says, motivated by an interplay of idiosyncratic social, economic and personal factors.

The shifting climate means that we must allow - and assist - people, plants and animals who are forced to relocate to survive. Instead of hardening our borders and fighting to prevent change at all costs, we should help migrants to move in a safe and orderly way. Context will tell us when specific moves - such as animal predators to remote islands - are unwise. But we must face the inevitable: our social, political and ecological world is changing substantially. The altered communities that result won't just be different, they'll often be better adapted to thrive in our warming world. As Shah writes, “We can turn migration from a crisis into its opposite: the solution."

Emma Marris is an environmental writer who lives in Klamath Falls, Oregon. e-mail: e.marris@gmail.com 